Resumen: "La televisión todo lo que toca lo convierte en contenido dramático. Es un relato más de acción que de reflexión; propone movimientos en las historias. La descripción densa y la reflexión argumental no son el fuerte televisivo. Para mover la acción se requiere el conflicto como motor de ese viaje. La narrativa televisiva siempre buscará el conflicto para poder generar drama, emoción y acción, desde la telenovela, el talk show hasta la Santa Misa" (Omar Rincón, 2006, p.181).

Las palabras de Omar Rincón sintetizan gran parte del estado narrativo de la televisión, y pueden ser perfectamente aplicadas a la información televisiva. Desde las ya conocidas formas de espectacularización, hasta la inclusión de formas narrativas como la ficcionalización y la dramatización, las noticias buscan, fundamentalmente, una producción de imágenes que respalden el sentido, y que documenten y que también generen impacto en el tratamiento informativo. Estudios de información televisiva realizados por la Defensoría del Público de Argentina demuestran una clara superioridad de noticias policiales en las perspectivas del tratamiento de la información.

Este trabajo aborda el tratamiento de la violencia en las noticias de la televisión argentina.

Palabras clave: información televisiva - violencia - espectáculo.

[Resúmenes en inglés y portugués en las páginas 141-142]

(1) Magister en Periodismo y Medios de Comunicación (UNLP). Profesor e Investigador de la Universidad Nacional de Quilmes y la Universidad Nacional de La Plata. Publicaciones recientes: "La Comunicación en los territorios. Experiencias en la construcción colectiva del conocimiento" y “Transiciones de la escena audiovisual. Perspectivas y disputas"

\title{
La violencia es noticia
}

Este artículo se terminó de escribir el 18 de febrero de 2020, exactamente un mes después de que un grupo de diez jóvenes asesinó a golpes a Fernando Báez Sosa, de 18 años, a la salida de un local nocturno de la ciudad balnearia de Villa Gesell. La única razón fue la 
misma por la que cada noche se libra una pelea en un boliche: el desmedido consumo de alcohol y de drogas o, lo que es peor, el acostumbramiento a vivir en un clima de violencia urbana, muchas veces injustificada.

Desde el 18 de enero, cuando tomó estado público la noticia, los medios de comunicación y, en particular, la televisión, emprendieron una cobertura del hecho casi en cadena nacional hasta el día de hoy, ofreciendo cobertura en espacios informativos, como los noticieros; en programas de espectáculos y farándula; y hasta en programas deportivos, producto de que algunos de los asesinos de Fernando son jugadores de rugby en la ciudad de Zárate, Provincia de Buenos Aires.

Cada programa de televisión daba paso al siguiente acercando actualidades sobre el acontecimiento, analizando, con fuertes opiniones, haciendo especulaciones, sancionando a las partes implicadas con argumentos policiales y judiciales, presentando pruebas y contrapruebas, o con el más explícito sentido común, producto de la inédita interpelación que el caso generó en la audiencia.

Como es sabido, la televisión es, aún, el medio audiovisual predominante en la construcción del sentido social cotidiano, fundamentalmente en materia informativa. Muchos debates teóricos anticipan su extinción frente a las nuevas pantallas móviles y redes sociales, pero el poderío en la instalación de la agenda sigue siendo de la televisión. Según la última Encuesta de Consumos Culturales realizada por el Sistema de Información Cultural de la Argentina (SInCA), dependiente del Ministerio de Cultura de la Nación, los noticieros o programas informativos son los programas más mirados en TV. En efecto, de cada 10 argentinos, 7 acostumbra mirarlos.

Por la naturaleza del medio audiovisual, la información televisiva ha desarrollado, a lo largo de su historia, un infinito número de recursos narrativos, argumentales, gramaticales y estilísticos que "educaron" la mirada de los televidentes ávidos por pruebas, imágenes de impacto e hiperrealidad, y acceso a aquellos lugares a los que el ojo no puede acceder. Un ejemplo de ello es el uso de la cámara oculta, que irrumpió con protagonismo durante la década de 1990. Fue cuestionado por muchos, pero se convirtió, en esos años, en el principal aliado del periodismo de investigación, considerando la necesidad explícita que tiene la televisión de registrar las pruebas testimoniales y documentales con imágenes de producción propia. Sin embargo, su uso generó una grieta entre quienes consideran que se trata de una invasión a la privacidad de las personas y quienes creen que una prueba contundente fortalece la posición del periodista frente a su nota. En estos años donde la producción de imágenes satelitales o cámaras de seguridad son una política de Estado tanto como la masificación de los smartphones y las redes sociales, la frontera entre las imágenes de la vida pública y la vida privada quedó absolutamente desdibujada.

\section{Violencia en la televisión}

La televisión todo lo que toca lo convierte en contenido dramático. Es un relato más de acción que de reflexión; propone movimientos en las historias. La descripción densa y la reflexión argumental no son el fuerte televisivo. Para mover la acción se requiere el conflicto como motor de ese viaje. La narrativa televisi- 
va siempre buscará el conflicto para poder generar drama, emoción y acción, desde la telenovela, el talk show hasta la Santa Misa (Omar Rincón, 2006).

Las palabras de Omar Rincón sintetizan gran parte del estado narrativo de la televisión, y pueden ser perfectamente aplicadas a la información televisiva. Desde las ya conocidas formas de espectacularización, hasta la inclusión de formas narrativas como la ficcionalización, la dramatización y la personalización, las noticias buscan, fundamentalmente, una producción de imágenes que respalden el sentido, y que documenten y generen impacto en el tratamiento informativo.

Estudios de información televisiva realizados por la Defensoría del Público de Argentina demuestran una clara superioridad de noticias policiales en las perspectivas del tratamiento de la información. En el último informe presentado, que releva el período 2018, "se distingue que las noticias policiales ocuparon un cuarto de todo el tiempo emitido en el año, mientras que el segundo tópico más utilizado, que es el de noticias políticas, rondó el $15 \%$. Esta disparidad entre la medida por cantidad y por duración de las noticias, que suele ser particularmente notable en ciertos tópicos ("Policiales e inseguridad", "Internacionales") es un rasgo reiterado en los monitoreos a lo largo de los años, y permite sacar conclusiones respecto de los énfasis mediáticos de los canales indagados. Así, mientras que las noticias policiales tomaron menos de un quinto del total de noticias presentadas, tomaron un cuarto del tiempo; a la vez que las noticias políticas participaron con un quinto del total tanto en cantidad como en duración".

Cuando se profundiza el estudio desde una perspectiva de noticias agrupadas o vinculadas, es decir, noticias que abordan dos tópicos, más de la mitad de las noticias son tematizadas bajo los tópicos Policiales e Inseguridad, y Política.

El último dato que resulta relevante destacar es que cuando se analizó "Policiales e inseguridad" como tema prevalente de la noticia, se observó que las principales asociaciones temáticas se dieron con "Niñez y Adolescencia/Juventud". De más está decir que el tratamiento informativo referido a la juventud está enfocado desde la perspectiva de lo policial o la inseguridad.

Como plantea Mariano Cebrián Herreros "los noticieros dejaron de ser un servicio de información para convertirse en programas que buscan captar a las audiencias como cualquier tipo de programa" (2004, p. 25). Incluso, con la aparición de los canales especializados en información que emiten 24 horas de noticias, los canales generalistas están obligados a desarrollar otras estrategias para distinguirse de los antes mencionados. Se modifica la organización en pirámide invertida, dando paso a nuevas estrategias de organización de la información: desde las ya conocidas formas de espectacularización, hasta la inclusión de formas narrativas como la ficcionalización, la entrega seriada de noticias, la inclusión de pauta publicitaria interna con secciones fijas auspiciadas y demás, pero, fundamentalmente, una dependencia de la producción de imágenes que respalden, documenten y produzcan impacto en los espectadores. 


\section{La imagen como fuente y narración}

"Un medio sin fuentes es un medio muerto" sentenció la catedrática española Mar de Fontcuberta en 1993. Este categórico concepto se desvaneció a partir de la transformación de la producción informativa.

Como viene mostrando el comportamiento de la producción informativa en televisión, el Informe anual de la Defensoría del público de los últimos seis años demostró que más de la mitad de las noticias no utilizó ni refirió ninguna fuente de información. Del resto, la mayoría refirió solo una fuente.

En el crimen de Fernando, el tratamiento informativo estuvo protagonizado, también, por la ausencia de fuentes o testimonios en primera persona. La madre de Fernando tuvo apariciones breves y planificadas, y cedió gran parte de la testimonialidad al abogado mediático Fernando Burlando y parte de su equipo; y los familiares de los agresores que lo golpearon hasta matarlo optaron organizadamente por el silencio. En consecuencia, las coberturas estuvieron, fundamentalmente, vacantes de fuentes testimoniales, con gran variedad de análisis generales; con psicólogos analizando la violencia explícita de la noche, de la juventud, del rugby, y del comportamiento en grupo; y con abogados que especulaban con los pormenores del procedimiento judicial, con la situación carcelaria, etc.

Lo que sí abundó, en este caso, es la aparición compulsiva de imágenes de todos los tipos: más de quince videos fueron incorporados a la causa judicial y ganaron presencia mediática al instante, circulando una y otra vez durante toda la programación.

El primero en aparecer fue el video de un testigo del ataque en la puerta del local nocturno Le Brique, que muestra con explícita crueldad las patadas que le pegaron en el piso a Fernando hasta ultimarlo. Esas imágenes de elevada violencia se naturalizaron en la televisión, y se convirtieron en la imagen de títulos. Ante el crecimiento de la demanda, aparecieron más videos que reconstruyeron integralmente el antes y el después de la escena del crimen sin conciencia de producir la prueba o exhibiendo un sentido identitario que resulta propio para estos jóvenes, pero que los medios se encargaron de resemantizar, es decir, invertir el sentido en favor del discurso mediático y, claramente, repudiado por la audiencia.

El peritaje de los teléfonos celulares de los agresores y la identificación de su producción en redes sociales construyen una suerte de "identidad digital", que produce un sentido social propio que se traslada del mundo privado al mundo público sin procesos de chequeo ni profesionalización. La vida se muestra en el mismo momento en que se la vive.

Los jóvenes plantean la visibilidad en términos de necesidad y de deseo: "me tengo que mostrar", "quiero que me vean".

¿De dónde nace esta compulsión de visibilidad? Rosalía Winocur plantea que "la visibilidad garantiza la inclusión en un mundo cuya representación se ha desplazado de lo palpable a lo comunicable. La clave que explica lo trascendente que se ha vuelto estar visible radica en lo amenazadora que resulta la invisibilidad" (2012, p. 81). En las redes sociales virtuales, estar visible significa estar presente. Para los jóvenes, no tener un perfil en Instagram es equivalente a faltar a la fiesta en la que están todos sus amigos. Así como ciertos espacios de socialización requieren de nuestra presencia física, en los espacios públicos virtuales nuestra visibilidad se vuelve un requerimiento. 
En última instancia, mostrarse es un medio para existir en este espacio. Lo que hacen los jóvenes es producir "una actuación con el objetivo de estar visible en los espacios significativos donde transcurre la sociabilidad -tanto on line como off line-, los cuales constituyen escenarios claves de recreación y dramatización de las nuevas formas de inclusión social" (Winocur, 2012, p. 81). La red social es una extensión de la sociabilidad en el mundo real. Así como necesitan existir en uno, tienen que ser visibles en la otra.

"No falta nada para irnos a Gessel a romper lo que nos faltó el año pasado" dice en su cuenta de Twitter Lucas Pertossi, uno de los jóvenes acusados del asesinato. Aparecieron videos grabados con sus teléfonos, compartidos, bebiendo alcohol antes de la salida nocturna; además de otros videos que prueban la presencia en el local bailable, e, incluso, el propio Lucas grabó el primer video de la primera agresión a Fernando. El desarrollo de la pelea dispara la atención de otros jóvenes que, en el lugar, encienden sus teléfonos para grabar, para documentar, para compartir. Máximo Thomsen, otro de los acusados, se deja ver como protagonista del ataque como líder de su manada.

Posterior al asesinato, entran en acción otras imágenes: las tomadas por las cámaras de seguridad. Primero se saludan, festejan, se abrazan: ganaron la batalla. Otra cámara los muestra deshaciéndose de las pruebas, limpiando la sangre de Fernando de sus manos, revisándose la ropa. Vuelven a la escena, con un audio que Lucas Pertossi comparte en el grupo de whatsapp: "caducó", lo que confirma la muerte. No se alteran. Van por una hamburguesa y las cámaras de McDonald's siguen la secuencia: piden por caja, buscan una mesa y comparten una comida como si no hubiera sucedido nada. Otras imágenes marcan el camino de vuelta a la casa de los agresores. Las imágenes llegan antes a la televisión que a la justicia.

La sucesión de videos construyó una secuencia del montaje tradicional norteamericano, utilizando recursos de imagen de acción, de fuentes públicas y privadas. Para la justicia, el recurso es genuino porque permite recoger insumos probatorios para la causa, pero la televisión acostumbra usar las cámaras de seguridad o la producción privada para construir sentido, interponiéndose a la Ley Nacional de Protección de Datos Personales. Son las mismas imágenes que, como suele ejemplificar el informe de la Defensoría del Público, construyen casi con exclusividad un tratamiento de la juventud desde un enfoque policial, violento e inseguro.

En consecuencia, la imagen se constituye como fuente documental, a la vez que como fuente identitaria, como fuente judicial y como fuente narrativa.

\section{Investigación sobre violencia televisiva}

El campo de la comunicación social y la sociología de los medios han desarrollado, por más de cinco décadas, estudios de los efectos en los públicos de la violencia representada en los medios de comunicación. A su vez, realizaron estudios acerca de las formas de representación social. Y, naturalmente, también de la relación entre la violencia, el cine y el arte.

En distintos países se crearon investigaciones para estudiar los efectos de la televisión, el crecimiento de los contenidos violentos, el rol de la publicidad en la construcción de estereotipos de consumo, y la información circunscripta a intereses comerciales, económicos, políticos, etc. 
En la historización de la investigación sobre la violencia televisiva, Manuel Garrido Lora marca un cambio en el enfoque de los estudios, expresando que "donde realmente se lleva a cabo la espectacularización de la violencia es en lo que Imbert denomina los derrapes, entendidos como recursos formales que enfatizan los hechos y que revelan la violencia del medio. Junto a la propia violencia de los hechos informados, hay también violencia en la forma de contarlos. Ese espectáculo de la violencia genera un escenario que incide directamente en la percepción de la realidad por parte de los ciudadanos.

En las imágenes, la pasión se desata y la violencia se convierte en espectáculo. De este modo, emerge un discurso sobre la violencia, centrado en la violencia social que invade las páginas de información (y de manera espectacular la primera plana) y hasta los editoriales y que cultiva una imaginería del miedo y de la inseguridad" (2002, p. 4).

La violencia en la forma de contar la realidad no es exclusiva de la televisión, pero la fortaleza de la imagen la potencia. La teoría de la hegemonía cultural de Pierre Bourdieu, llamada violencia simbólica, designa la dominación de la sociedad por su clase dominante, y se convierte en la norma cultural aceptada y en la ideología dominante, válida y universal. La hegemonía cultural justifica el statu quo social, político y económico como natural e inevitable, y ha servido para la estigmatización del tratamiento de la mujer, de los grupos migrantes, y de otras culturas no hegemónicas, tanto políticas, como culturales o religiosas.

El impacto del tratamiento informativo del asesinato de Fernando Báez Sosa no solo se convirtió casi exclusivamente en el tema único de la televisión, sino que, también, alimentó la presencia de temas vinculados, como la aparición de otros acontecimientos de violencia urbana protagonizados por jóvenes, por rugbiers, con la producción de imágenes como actor central.

El futuro será protagonizados por el monotema de su tiempo, una nueva pandemia, el evento deportivo del año o el caso de corrupción del momento. Pero esa es otra historia.

\section{Bibliografía}

Bourdieu, Pierre (1997). Sobre la televisión. Editorial Anagrama: Barcelona.

Cebrián Herreros, Mariano (2004). La información en televisión. Obsesión mercantil y política. España: Editorial Gedisa.

De Fontcuberta, Mar (1993). La Noticia. Pistas para percibir el mundo. Barcelona: Paidós Papeles de Comunicación.

Defensoría del público de la comunicación audiovisual. Dirección de Análisis, Investigación y Monitoreo. Monitoreos de Noticieros Televisivos de Canales de Aire de la Ciudad de Buenos Aires 2013-2018. Buenos Aires.

Farre, Marcela (2004). El noticiero como mundo posible. Estrategias ficcionales de la información audiovisual. Buenos Aires: La Crujía ediciones.

Garrido Lora, Manuel (2002). 40 años de investigación de los efectos de la violencia en prensa y televisión. México: Razón y Palabra.

Cebrián Herreros, M. (2004). La información en televisión. Obsesión mercantil y política. España: Editorial Gedisa. 
Mangifesta, Laura (2019). Tesis de grado "Instantáneas de una época: imagen, intimidad e identidad de los jóvenes del Conurbano Bonaerense Sur en Instagram”. Argentina: Universidad Nacional de Quilmes.

Martini, Stella. (2000). "El estudio de la noticiabilidad", en Periodismo y noticiabilidad. Argentina: Editorial Norma.

Martini, Stella (2000b). "Los sistemas clasificatorios de las noticias”, en Periodismo y noticiabilidad. Argentina: Editorial Norma.

Rincón, Omar (2006). Narrativas Mediáticas. O cómo se cuenta la sociedad del entretenimiento. "Capítulo 6: Narrativas de la radio". España: Ed. Gedisa.

Sibilia, Paula (2017). La intimidad como espectáculo. Colombia: Fondo de Cultura Económica.

Winocur, Rosalía (2012). “Transformaciones en el espacio público y privado. La intimidad de los jóvenes en las redes sociales”, en Telos, número 91, pp. 79-88. España: Fundesco.

Encuesta de Consumos Culturales realizada por el Sistema de Información Cultural de la Argentina (SInCA), dependiente del Ministerio de Cultura de la Nación. (2017)

Defensoría del Público de Servicios de Comunicación Audiovisual. (2019) Dirección de Análisis, Investigación y Monitoreo. Monitoreo de Noticieros Televisivos de Canales de Aire de la Ciudad de Buenos Aires. Argentina

\begin{abstract}
Television everything it touches turns it into dramatic content. It is a story more of action than of reflection; he proposes movements in the stories. The dense description and the argument reflection are not the strong television. Moving action requires conflict as the engine of that journey. The television narrative will always seek conflict in order to generate drama, emotion and action, from the soap opera, the talk show to the Holy Mass "(Omar Rincón, 2006, p. 181).

Omar Rincón's words synthesize much of the narrative state of television, and can be perfectly applied to television information. From the already known forms of spectacularization, to the inclusion of narrative forms such as fictionalization and dramatization, the news seeks, fundamentally, a production of images that support meaning, and that document and that also generate an impact on the informative treatment. Studies of television information carried out by the Public Defender of Argentina show a clear superiority of police news in the perspectives of the treatment of information.

This work deals with the treatment of violence in the Argentine television news.
\end{abstract}

Keywords: Television information - violence - Spectacle.

Resumo: "A televisão em tudo que toca transforma em conteúdo dramático. É uma história mais de ação do que de reflexão; ele propõe movimentos nas histórias. A descrição densa e a reflexão do argumento não são a televisão forte. A ação movente requer conflito como o mecanismo dessa jornada. A narrativa televisiva sempre buscará conflito para 
gerar drama, emoção e ação, da novela, do programa de entrevistas à Santa Missa "(Omar Rincón, 2006, p.181).

As palavras de Omar Rincón sintetizam grande parte do estado narrativo da televisão e podem ser perfeitamente aplicadas às informações da televisão. Desde as formas já conhecidas de espetacularização, até a inclusão de formas narrativas como ficcionalização e dramatização, as notícias buscam, fundamentalmente, uma produção de imagens que apóiem significado e que documentem e que também gerem impacto no tratamento informativo. Os estudos de informações televisivas realizados pelo Defensor Público da Argentina mostram uma clara superioridade das notícias policiais nas perspectivas do tratamento da informação.

Este trabalho trata do tratamento da violência no noticiário da televisão argentina.

Palavras chave: Informação televisiva - violência - Espetáculo.

[Las traducciones de los abstracts fueron supervisadas por el autor de cada artículo] 